Litter weight at 21 days and milk production of the sow permit to distinguish between three different groups : the best performance was observed in seven genetic types (the five «prolific» types and the two European breeds, LW and LF). The poorest results were obtained in two purebreeds ( $\mathbf{J X}$ and $\mathbf{J H}$ ), with half bred $\mathrm{JH}$ occupying an intermediate position.

On the basis of the intake of concentrate feed during lactation, we may distinguish between three groups whose means were significantly different : European sows (LW and LF) consumed 28 to $47 \mathrm{~kg}$ more than a group of seven genetic types (6 types of $\mathrm{F} 1$ and purebred MS), and about $70 \mathrm{~kg}$ more than purebred JX and JH sows.

In conclusion, these preliminary results seem to indicate that an appropriate cross between certain Chinese breeds (MS and JX) and an European breed (LW and LF) allows to use a F1 sow which has its first farrowing at least one month earlier, which is more economic (at least $100 \mathrm{~kg}$ of concentrate feed saved each year), and is more productive ( 5 to 7 more piglets weaned per year). As a consequence of that, the cost price of a weaned piglet can be reduced by 35 to 45 francs.

\title{
First results of experiments with chinese pigs in France \\ 2. Estimation of prolificacy factors : ovulation rate and foetal survival
}

\author{
P. ROMBAUTS *, G. MAZZARI **, F. DU MESNIL DU BUISSON * \\ *I.N.R.A., Station centrale de Physiologie animale, \\ F 78350 Jouy-en-Josas \\ ** Centre national de Recherches agronomiques, Maracay, Venezuela
}

To analyse the reasons for the prolificacy of Chinese breeds, Jia Xing (JX) and Mei Shan (MS), the ovulation rate of eleven 5-month old nulliparous sows was studied by coelioscopy for 5 successive cycles. The mean number of corpora lutea was 15.9 in the Jia Xing breed and 14.7 in the Mei Shan, i.e. it was comparable to Large White (LW) or French Landrace (LF) of about the same age.

The same observations were carried out for 4 cycles on $\mathrm{F}_{1}$-crossbred sows with a $\mathrm{Mei}$ Shan, Jia Xing or Jin Hua $(\mathrm{JH})$ father and a LW or LF mother. The effect of hybrid vigor was marked for this character in the JX-LF $(20.6 \pm 2.9$ ovulations) and JX-LW (16.7 $\pm 1,9$ ovulations).

These $F_{1}$ crosses (4 sows per group) were then slaughtered on day 50 of gestation to estimate the characteristics of gestation and calculate embryonic mortality. The percentage of embryonic survival and the number of live foetuses for the different groups were : 90.9 and 13.25 (JH-LF), 77.75 and 12.5 (JH-LW), 89.0 and 15.25 (MS-LF), 68.7 and 13.0 (MS-LW), 59.25 and 13.75 (JX-LF), 48.7 and 10.25 (JX-LW).

After day 50 of gestation, the number of foetuses in these sows was higher than in nulliparous Large White or Landrace sows. In the Mei Shan crosses, the large number of foetuses was associated with a particularly large uterine development. 